\title{
Relações de trabalho na mineração: análise dos acordos coletivos firmados entre o Sindicato Metabase Inconfidentes e a Vale S.A. com validade no período de 2009 a 2018
}

\begin{abstract}
RESUMO
Este artigo analisa e discute os acordos coletivos firmados entre o Sindicato Metabase Inconfidentes e a Vale S.A. com validade no período de 2009 a 2018. Assume a teoria social crítica, especialmente a Teoria Marxista da Dependência, para fundamentar a crítica ao modo de produção capitalista e a sua configuração a partir da dependência e da superexploração da força de trabalho neste território e explicitar que a luta de classes está presente nos acordos coletivos firmados. Os dados foram agrupados em quatro cláusulas e foram organizados em tabelas, sendo: 1) Cláusulas trabalhistas; 2) Cláusulas sociais; 3) Acordos e Benefícios referentes à área da saúde e 4) Acordos e Benefícios referentes à área da família. Como resultado da análise, demonstra-se a conquista e a manutenção de direitos, bem como a perda de benefícios ao longo dos anos analisados. Demarca-se a importância e a necessidade da organização coletiva dos trabalhadores para fazer frente à necessidade de o capital retomar as taxas de lucro neste contexto produtivo. Ressalta-se a atuação do Sindicato Metabase Inconfidentes enquanto uma entidade combativa e alinhada aos interesses da categoria profissional que representa e da classe trabalhadora como um todo. Por fim, esta discussão intenta contribuir com a luta sindical dos trabalhadores da mineração na região Inconfidentes de Minas Gerais.
\end{abstract}

Palavras-chave: Acordos coletivos. Mineração. Relações de trabalho. Organização da classe trabalhadora. Direitos trabalhistas.

\footnotetext{
${ }^{1}$ Graduada em Serviço Social pela Universidade Comunitária Regional de Chapecó - UNOCHAPECÓ. Mestra e Doutora em Serviço Social pela Universidade Federal de Santa Catarina - UFSC. É professora do departamento de Serviço Social da Universidade Federal de Ouro Preto - UFOP, Campus Mariana, MG, Brasil. E-mail: kathibertollo@gmail.com.

${ }^{2}$ Graduada em Serviço Social pela Universidade Federal de Ouro Preto - UFOP, Campus Mariana, MG, Brasil. E-mail: neidireis@gmail.com.
} 


\title{
Mining work relations: analysis of collective agreements signed between the Metabase Inconfidentes Union and Vale S.A. valid from 2009 to 2018
}

\begin{abstract}
This article analyzes and discusses the collective agreements signed between the Metabase Inconfidentes Union and Vale SA with validity from 2009 to 2018. It assumes the critical social theory, especially the Marxist Theory of Dependency to support the criticism of the capitalist mode of production and its configuration based on the dependence and overexploitation of the labor force in this territory and to explain that the class struggle is present in the collective agreements signed. The data were grouped into four clauses and were organized in tables, as follows: 1) Labor clauses; 2) Social clauses; 3) Agreements and Benefits referring to the health area and 4) Agreements and Benefits referring to the family area. As a result of the analysis, it demonstrates the conquest and maintenance of rights, as well as the loss of benefits over the years analyzed. It highlights the importance and the need for the collective organization of workers to face the need for capital to resume profit rates in this productive context. The performance of the Metabase Inconfidentes Trade Union is highlighted as a combative entity and aligned with the interests of the professional category it represents and the working class as a whole. Finally, this discussion intends to contribute to the union struggle of mining workers in the Inconfidentes region of Minas Gerais.
\end{abstract}

Keywords: Collective Agreements. Mining. Labor Relations. Working Class Organization. Labor Rights.

Artigo recebido em: 03/08/2020

Aceito em: 08/10/2020 


\title{
1. INTRODUÇÃO
}

Nas linhas que seguem serão analisados e discutidos os acordos coletivos firmados entre o Sindicato Metabase Inconfidentes e a Vale S.A. com validade no período de 2009 a 2018 ${ }^{3}$. Para tanto, assumimos como percurso teórico e analítico a teoria social crítica, especialmente a Teoria Marxista da Dependência (TMD), para fundamentar a crítica ao modo de produção capitalista e a sua configuração a partir da dependência e da superexploração da força de trabalho neste território. As formulações de MARX (2013) explicitam o caráter fetichizado da mercadoria e o processo de trabalho em que uma mercadoria especial é comprada e vendida, a força de trabalho. É neste processo de trabalho assalariado, relação que se dá entre os detentores dos meios de produção e aqueles que possuem apenas a sua força de trabalho como forma de sobrevivência, que se põem e se explicitam a exploração e a produção de mais valor.

Ao assumir tais premissas como fundamento do modo de produção capitalista consideramos fundamental considerar as particularidades em que o capitalismo e o processo de produção capitalista vão se generalizando e se estabelecendo como processos hegemônicos no globo como um todo.

Ruy Mauro Marini, um dos formuladores da Teoria Marxista da Dependência (TMD), explicita e argumenta acerca da condição de capitalismo dependente que se põe ao continente latino-americano, aos seus Estados-nações e povos no contexto da divisão internacional do trabalho. A situação que se impõe é de subordinação econômica para com os centros capitalistas europeus, o que conforma o processo de produção a partir da superexploração da força de trabalho e da dependência. Nas palavras do autor "a inserção da América Latina no mercado mundial contribui para desenvolver o modo de produção especificamente capitalista, que se baseia na mais-valia relativa". (MARINI, 2005, p. 146)

O mesmo autor prossegue explicitando acerca da superexploração da força de trabalho, fundamento da dependência, e afirma que:

\begin{abstract}
A intensificação do trabalho, a prolongação da jornada de trabalho e a expropriação de parte do trabalho necessário ao operário para repor sua força de trabalho - configuram um modo de produção fundado exclusivamente na maior exploração do trabalhador, e não no desenvolvimento de sua capacidade produtiva. Isso é condizente com o baixo nível de desenvolvimento das forças produtivas na economia latino-americana, mas também com os tipos de atividades que ali se realizam. (MARINI, 2005, p. 156)
\end{abstract}

\footnotetext{
${ }^{3}$ Este artigo é dedicado à Memória de Bruno Augusto Carrilho Coga, militante da mineração em Minas Gerais. Sua contribuição foi fundamental para a realização deste estudo.
} 
$\mathrm{O}$ autor prossegue afirmando que:

[...] na indústria extrativa e na agricultura o efeito do aumento de trabalho sobre os elementos do capital constante são muito menos sensíveis, sendo possível, pela simples ação do homem sobre a natureza, aumentar a riqueza produzida sem um capital adicional. Entende-se que nestas circunstâncias, a atividade produtiva baseia-se sobretudo no uso extensivo e intensivo da força de trabalho: isso permite baixar a composição-valor do capital, o que, aliado à intensificação do grau de exploração do trabalho, faz com que se elevem simultaneamente as taxas de mais valia e lucro. (MARINI, 2005, p. 156)

Assim, para explicitar e refletir sobre as relações de trabalho e os acordos coletivos, é imprescindível considerar a configuração, a partir da dependência e da superexploração da força de trabalho (MARINI, 2005), da América Latina e deste território em estudo, a região de abrangência do Sindicato Metabase Inconfidentes, e explicitar acerca do período recente, dando ênfase ao chamado boom e pós-boom das commodities, questão que as autoras entendem estar diretamente relacionada com os rompimentos das barragens/crimes ocorridas em Minas Gerais.

A partir desta condição histórica são apontados os dilemas e desafios colocados à organização sindical da classe trabalhadora brasileira em tempos pretéritos e na contemporaneidade, dando ênfase à atuação e à organização do Sindicato Metabase Inconfidentes nas lutas gerais da classe trabalhadora e na pactuação dos já mencionados acordos coletivos. Explicitamos que a luta de classes está presente nos documentos firmados, seja pela luta e resistência dos trabalhadores organizados e representados pelo sindicato seja pela ofensiva exploratória da mineradora, uma vez que os documentos demonstram a conquista e a manutenção de direitos, bem como a perda de benefícios ao longo dos anos analisados.

Em meio a esse conjunto de elementos, demarcamos a importância e a necessidade da organização coletiva dos trabalhadores para fazer frente à superexploração da força de trabalho, à destruição ambiental e às mortes decorrentes da necessidade de o capital retomar as taxas de lucro neste contexto produtivo. Nesse sentido, ressaltamos a atuação do Sindicato Metabase Inconfidentes enquanto uma entidade combativa e alinhada aos interesses da categoria profissional que representa e da classe trabalhadora como um todo.

Por fim, esta discussão intenta contribuir com a luta sindical dos trabalhadores da mineração na região Inconfidentes de Minas Gerais. 


\title{
2. CAPITALISMO DEPENDENTE E O CONTEXTO DA MINERAÇÃO EXTRATIVISTA EM MINAS GERAIS
}

Minas Gerais ocupa lugar emblemático no globo quando se pensa acerca da mineração, seja pelo seu passado rico em ouro, diamantes e outros metais preciosos que foram expropriados pelas metrópoles europeias, ou pelo seu presente, em que o minério de ferro ocupa a referência central da extração mineral, produção esta que é direcionada prioritariamente ao exterior, aos grandes centros imperialistas e em desenvolvimento. Assim, neste chão a riqueza e a pobreza, âmbitos imbricados, porém contrastantes, decorrem de e são fomentados pela atividade mineral.

A América Latina, o Brasil, o estado de Minas Gerais e seus inúmeros municípios em que ocorre a exploração mineral são territórios conformados pela lógica do capitalismo dependente e da superexploração da força de trabalho (BERTOLLO, 2017). É o lugar, posição e condição relegados a esses no âmbito da divisão internacional do trabalho. "Temos um sistema mundial que opera com núcleos e acumulação de valor em contraste com amplos territórios que sofrem de desacumulação" (OSÓRIO, 2012, p. 76). Nesse sentido, o mesmo autor prossegue afirmando que,

\begin{abstract}
os processos que permitem a transferência de valores de uma região e uma economia para outras variam no tempo. Se na etapa colonial isso era possível por meios preferencialmente políticos (as colônias entregando tributos e impostos às metrópoles ou sofrendo despojos de riquezas e metais preciosos pela simples condição colonial), posteriormente tal processo tende a se apoiar de maneira predominante em mecanismos econômicos (deterioração nos termos de intercâmbio ou intercâmbio desigual, pagamento de royalties, transferência devido ao monopólio de conhecimentos, juros da dívida, etc.). (OSÓRIO, 2012, p.77)
\end{abstract}

Esses elementos determinantes conformam e estruturam historicamente a produção mineral no país, em Minas Gerais e particularmente nos municípios da chamada Região Inconfidentes, que demonstraram ter expressiva dependência econômica e política da atividade de extração de minério de ferro, uma vez que vivenciaram fortemente os impactos dos ciclos de boom e pós-boom das commodities que resumidamente podem ser compreendidos da seguinte forma:

A primeira parte do ciclo, que durou até 2011, corresponde à fase de constante e aguda valorização nos preços de várias commodities minerais no mercado internacional. O minério de ferro de $62 \%$ de teor que, em maio de 2002 , custava US\$ 12,60 a tonelada, chegou a US\$ 187,10 em janeiro de 2011, uma valorização de quase 15 vezes em 10 anos. [...] Até 2011, o setor da mineração se comportava como se o crescimento da demanda e dos preços fosse se manter crescente, não 
restringindo novos investimentos e aquisições e sem limites para a expansão da fronteira mineral. A partir 2012, com o alastramento da crise econômica global, em especial para a Europa, e com a desaceleração do crescimento da economia na China, os preços das commodities minerais entram em decrescimento. [...] o minério de ferro voltou a US\$39,60 a tonelada, queda de 79\%. (WANDERLEY, 2017, p 01)

A partir dessas movimentações econômicas no âmbito do comércio mundial de commodities, pode-se dizer que o período de boom se caracterizou pelo alto preço e expressiva demanda de minério de ferro; já o período denominado de pós-boom foi marcado pelo excesso de oferta no mercado internacional e pela retração da demanda global e, mais especificamente, chinesa, o que ocasionou preços mais baixos.

Essa oscilação determinada pela crise econômica mundial influenciou diretamente o âmbito da produção e das relações de trabalho na mineração em Minas Gerais. Agravaramse as condições laborais e sociais dos trabalhadores. A comprovação máxima desse contexto foi o rompimento da barragem/crime de Fundão ocorrido em 05 de novembro de 2015. Fato/crime este que está intimamente relacionado ao descaso e à omissão da mineradora para com os seus trabalhadores e para com a comunidade em seu entorno, bem como, ao objetivo primordial de retomar os patamares de lucratividade afetados pelo período de baixa nos preços e na demanda.

Nesse sentido, torna-se relevante explicitar o posicionamento do Sindicato Metabase Inconfidentes frente à situação laboral dos trabalhadores e ao ocorrido:

\begin{abstract}
O Sindicato Metabase Inconfidentes e a CSP-Conlutas se solidarizam com as vítimas e se colocam à disposição dos trabalhadores e das comunidades neste momento de dor e sofrimento. Também nos colocamos à disposição do Metabase Mariana, representante dos trabalhadores da Samarco Mineração para juntos, darmos uma resposta do conjunto do movimento sindical para este grave problema causado pela Samarco. A política da Samarco para com os trabalhadores e as comunidades é a mais perversa possível. Uma empresa que lucra bilhões todos os anos e investe muito pouco em seus trabalhadores, em segurança e nas cidades. Há aproximadamente um mês, a CSP- Conlutas divulgou um boletim informativo com uma grave denúncia sobre o aumento dos acidentes de trabalho na empresa. Mesmo diante da grave situação de risco, a Samarco manteve sua produção, sem se preocupar com os riscos de acidentes iminentes. Para as grandes mineradoras, o mais importante é o lucro. A preocupação com a vida dos trabalhadores e das comunidades é secundarizada. (CAHIS CONTRACORRENTE, 2005)
\end{abstract}

Essa situação tênue entre a vida e a morte no contexto laboral da mineração extrativista, de exaurimento precoce da força de trabalho pelos constantes acidentes e turnos de trabalho, de destruição abrangente, alastrada e definitiva da natureza é marca histórica de nossa conformação enquanto país de capitalismo dependente, subordinado econômica e politicamente aos ditames e aos interesses dos centros imperialistas e da superexploração da 
força de trabalho, condição de cotidiano e de vida imposta aos trabalhadores. Assim, é fundamental a organização da classe trabalhadora para tensionar e fazer frente a essas questões estruturais das esferas da produção e reprodução social sob a hegemonia do capital.

\section{ORGANIZAÇÃO SINDICAL DA CLASSE TRABALHADORA BRASILEIRA: CONSIDERAÇÕES SOBRE O SINDICATO METABASE INCONFIDENTES}

É pelo número de sócios que se mede a força do sindicato. O Sindicato não é só um prédio, nem é somente seus diretores, o Sindicato é a organização de todos os trabalhadores e deve estar a serviço dos trabalhadores. (ILAESE; SINDICATO METABASE INCONFIDENTES, 2017, p 20)

A organização sindical da classe trabalhadora brasileira tal qual como conhecemos hoje decorre de processos históricos, políticos e de resistência que têm origem mesmo antes da abolição da escravatura no país. É imperioso reconhecer os 'levantes' ocorridos nos centros urbanos e desencadeados pelos trabalhadores escravizados e que tiveram o apoio dos trabalhadores livres. Essa atuação conjunta já explicitava "valores da nova classe em formação" e já incluía "o compartilhamento de modelos e formas associativas, assim como de padrões de mobilização e luta [...] que se desdobra para além da abolição" (MATTOS, 2009, p 21-24). Dos 'levantes' e 'associações de ajuda mútua' à primeira 'greve' no país em 1858, a formação da classe trabalhadora e a conformação tal qual a conhecemos na atualidade foi forjada no âmbito da luta de classes e da posição ocupada na divisão social do trabalho.

Ao conformar-se como modo de produção hegemônico, o capitalismo vai configurando e impondo a chamada divisão internacional do trabalho, em que os territórios/Estados-nações ocupam posições distintas; bem como, configura e acirra a luta entre as classes sociais fundamentais. Nesse cenário econômico global, o lugar ocupado pelo continente latino-americano é de dependência e a classe trabalhadora latino-americana é submetida à superexploração da força de trabalho. Tal conformação histórica é reafirmada e ganha novos e agravados contornos a partir das últimas décadas do século $\mathrm{XX}$, com a ofensiva neoliberal (que pressupõe a venda/privatização dos bens públicos e o desmonte do Estado no que se refere ao atendimento via políticas públicas e legislações de proteção ao 
trabalhador/a, dentre outros aspectos), com a chamada reestruturação produtiva ${ }^{4}$ (que diz respeito às inúmeras transformações e modificações no processo produtivo e nas relações laborais decorrentes da expressiva incorporação da tecnologia, do desemprego, das modificações das formas de vínculos trabalhistas, dentre outros aspectos) e com a financeirização da economia ${ }^{5}$ (situação influenciada e conformada pela mundialização do capital, pela divisão internacional do trabalho, pela produção em escala global, pela comercialização de produtos que ainda serão produzidos, ou seja, a partir de uma projeção de sua produção a sua comercialização é realizada - tal como acontece com a produção de várias commodities, como a soja, por exemplo, dentre outros aspectos) estratégias estas que orientam o capital na busca pela retomada das taxas de lucro e fazem com que as relações laborais permaneçam pautadas pela exploração de uma classe sobre a outra, exploração esta que se acentua cotidianamente. Esse é o cenário a partir do qual a classe trabalhadora brasileira se constituiu ao longo dos séculos e que impõe desafios ímpares ao seu fortalecimento e organização sindical na contemporaneidade.

É imperioso destacar que a classe trabalhadora brasileira é conformada historicamente pelo processo de escravidão e, posteriormente, pela dominação imperialista, o que a subordina a adversas e restritas possibilidades de sobrevivência, ou seja, um contingente de homens e mulheres, adultos, crianças, jovens e idosos são cotidianamente submetidos ao trabalho informal, ao desemprego estrutural e à superexploração da força de trabalho.

Acerca da Região dos Inconfidentes, território de abrangência e atuação do Sindicato ora em evidência, destaca-se que a principal fonte e atividade econômica é a mineração extrativista de minério de ferro. Os trabalhadores representados por esse sindicato residem majoritariamente nos municípios de Congonhas - MG, Mariana - MG e Ouro Preto - MG. Esses municípios cresceram populacionalmente e se conformaram de vilas a cidades de médio porte por meio das riquezas minerais próprias dessa região do país. A configuração resultante de que os municípios não possuem outras atividades produtivas que sejam expressivas economicamente como a mineração condiciona parte significativa da população

\footnotetext{
${ }^{4}$ Para maior aprofundamento consultar a produção teórica de Ricardo Antunes, na qual destacamos as obras: Adeus ao trabalho?: ensaio sobre as metamorfoses e a centralidade do mundo do trabalho. 11. ed. São Paulo: Cortez; Campinas: Universidade de Campinas, 2006; Trabalho e precarização numa ordem neoliberal. In: GENTILI, P.; FRIGOTTO, G. (Orgs). A cidadania negada: Políticas de exclusão na educação e no trabalho. São Paulo: Cortez, 2001, p. 35-48; Riqueza e miséria do trabalho no Brasil. Ricardo Antunes (Org.). São Paulo: Boitempo, volumes I, II e III.

${ }^{5}$ Para maior aprofundamento consultar artigo científico intitulado: Dialética do desenvolvimento periférico: dependência, superexploração da força de trabalho e política econômica de autoria de Marcelo Dias Carcanholo e publicado na R. Econ. contemp., Rio de Janeiro, v. 12, n. 2, p. 247-272, maio/ago. 2008. Disponível em: https://www.scielo.br/pdf/rec/v12n2/03.pdf.
} 
residente a vender sua força de trabalho às mineradoras que ali estão situadas. Destaca-se que, no ano de 2013, o município de Ouro Preto - MG possuía 5.200 pessoas trabalhando no setor de serviços e 5.667 na mineração. Em Mariana - MG, município vizinho, neste mesmo ano, 4.660 pessoas estavam empregadas no setor de serviços e 1.633 na mineração. Após o rompimento da barragem/crime de Fundão ocorre uma queda dessas estimativas, passando para 1.059 pessoas empregadas na mineração e 3.902 no setor de serviços no ano de 2016 (LAMPIÃO, 2019). Em suma,

explicita-se uma realidade em que a parcela de renda a qual a maior parte da população tem acesso é aquela que possibilita apenas o suficiente para manter biologicamente viva uma singular mercadoria - a força de trabalho, nada, além disso; o que remete estes indivíduos historicamente ao lugar de sujeitos superexplorados, seja no setor minerário extrativo ou no setor de serviços e de construção que servem de suporte para que o primeiro aconteça e se perpetue no município. (BERTOLLO, 2017, p. 160)

Importa destacar ainda que a relação entre a Compensação Financeira pela Exportação de Recursos Minerais (CFEM) e o Índice de Desenvolvimento Humano (IDHM) não ocorre de maneira proporcional, pelo contrário, reafirma a perpetuação da desigualdade entre as classes sociais neste território e a partir das riquezas por ele geradas. No ano de 2010, Mariana - MG ocupava a $3^{\mathrm{a}}$ posição no ranking estadual de arrecadação da CFEM e a $52^{\mathrm{a}}$ posição no ranking do IDHM. Situação semelhante ocorre com o município de Ouro Preto - MG, que ocupava a $11^{\mathrm{a}}$ e a $57^{\mathrm{a}}$ posição respectivamente (LAMPIÃO, 2019).

Diante desse cenário, aponta-se que somente com organização coletiva será possível potencializar as lutas e a resistência dos trabalhadores vinculados ao contexto da mineração extrativista nesta região. Assim, é mister reconhecer o sindicato "como o instrumento de representação de interesses coletivos mais próximo ao mundo do trabalho" (MATTOS, 2009, p. 09) e requisitar uma organização e atuação classista e autônoma, rechaçando qualquer postura atrelada ao Estado, de apaziguamento das lutas e pautas reivindicatórias, e de mera instância prestadora de serviços; situação esta, que vem marcando fortemente a ação e estruturação sindical do país nas últimas décadas e que se manifesta no setor produtivo da mineração.

\footnotetext{
A Vale tem buscado aproximar as direções sindicais de seus interesses, as subordinando de diferentes formas. No Brasil, uma das principais táticas têm sido o apoio à formação de chapas que disputem a direção dos sindicatos, além da demissão de funcionários que se disponham a formar chapas de oposição à Vale e da inviabilização das mesmas. (MILANEZ et al., 2018, p. 25)
} 
Em nosso entendimento e constatação, a postura sindical de mitigação das pautas e da organização coletiva não está presente na realidade organizativa e interventiva do Sindicato Metabase Inconfidentes, pelo contrário, histórica e cotidianamente ele "se posiciona explícita e fortemente a favor dos interesses dos trabalhadores e contra os desmandos do capital/empresas mineradoras" (BERTOLLO, 2017, p. 227), se constituindo como um sindicato de referência em nível nacional e internacional no que diz respeito à organização dos trabalhadores e às lutas travadas no contexto da mineração.

O Metabase Inconfidentes está há décadas na luta dos (as) operários (as) da mineração nas cidades de Congonhas, Ouro Preto/Mariana e região em MG, além de travar campanhas nacionais e internacionais em defesa da classe trabalhadora! (ILAESE, 2017, p. 70)

Essa postura interventiva, de atuação de modo amplo e articulado ao máximo de trabalhadores possível, reflete-se desde o processo histórico de conformação da atual estrutura organizativa e territorial do Metabase Inconfidentes. Essa decorreu da união entre o Metabase Timpopeba e o Sindicato distrital de Antônio Pereira - Ouro Preto - MG com o Metabase de Congonhas - MG, que, dessa forma, passou a representar os trabalhadores da Indústria de Extração de Ferro e Metais Básicos dos municípios de Congonhas - MG, Belo Monte - MG e Ouro Preto - MG.

A partir dessa configuração, a sede passa a se localizar no município de Congonhas MG, sendo que, em Mariana - MG, o sindicato possui uma subsede. Isso se explica pela proximidade geográfica e melhor condição de atuar politicamente junto aos trabalhadores, em especial aos da Mina Timbopeba, que se localiza no distrito de Antônio Pereira - Ouro Preto - MG, mas que fica muito próximo do centro urbano de Mariana - MG; local em que a maioria dos trabalhadores reside, acessa o comércio e o setor de serviços, dentre outros elementos. Nesse sentido, importa destacar que:

o processo de luta junto aos trabalhadores e consequentemente junto às comunidades dos municípios mineradores acontece por meio de assembleias, participação e realização de debates públicos, assessoria junto aos trabalhadores, dentre outras ações que vão além das pautas locais e da categoria, uma vez que se alinham a questões que atingem e marcam a vida da classe trabalhadora como um todo. (BERTOLLO, 2017, p. 228)

Além dessas formas de atuação, o Sindicato Metabase Inconfidentes mantém uma página na rede social Facebook em que, de imediato, explicita seu posicionamento ao afirmar que "está na luta em defesa dos trabalhadores e de uma sociedade mais justa" 
(SINDICATO METABASE INCONFIDENTES, 2019). Esse espaço serve como mais um canal de divulgação dos informes-boletins do sindicato, publicização de registros fotográficos e em vídeo de ações realizadas junto aos trabalhadores e da posição da diretoria perante as causas organizativas do contexto produtivo e laboral da mineração na região. Também são socializadas informações sobre o impacto e a importância de se combater as ofensivas do capital e do Estado por meio da restrição de direitos trabalhistas, da contrarreforma ${ }^{6}$ da previdência social, dentre outras pautas atreladas ao conjunto da classe trabalhadora. Por fim, explicita-se que o sindicato é filiado à CSP-Conlutas Central Sindical e Popular e, dessa forma, pauta a questão da organização, luta e resistência dos trabalhadores da mineração na Região Inconfidentes junto a outros sindicatos e movimentos sociais do país e em nível internacional.

\section{ANÁLISE DOS ACORDOS COLETIVOS FIRMADOS ENTRE O SINDICATO METABASE INCONFIDENTES E A VALE S.A. NOS ANOS DE} 2009 A 2018

A análise dos acordos foi realizada por meio de pesquisa bibliográfica e documental. Foram analisadas as informações contidas em cada acordo coletivo, dando ênfase para cada ano do período em que foram firmados e em que possuíam validade. Esses dados foram relacionados e analisados a partir de bibliografia pertinente ao tema, ou seja, buscamos subsídios teóricos que possibilitassem uma melhor compreensão e reflexão do conteúdo pactuado entre as partes. O acesso aos acordos coletivos se deu através do Sindicato Metabase Inconfidentes, que disponibilizou cópia dos documentos para que o estudo fosse realizado pelos autores.

Foram analisados os acordos coletivos firmados entre o Sindicato Metabase Inconfidentes e a Vale S.A. com validade no período de 2009 a 2018. Isso significa dizer que o último acordo analisado foi aquele firmado no ano de 2017, mas que teve sua vigência também ao longo de meses do ano civil de 2018, quando foi assinado o acordo coletivo referente ao ano de 2018, que adentrou o ano civil de 2019, e assim sucessivamente. Destacase que os acordos são pactuados nos meses de outubro/novembro, a depender do contexto de negociações. O período de um ano de validade desse documento ultrapassa o limite do ano civil corrente e adentra o calendário/meses do ano seguinte. A fim de abranger todo o

\footnotetext{
${ }^{6}$ Para maior aprofundamento acerca da categoria 'contrarreforma' indicamos a obra intitulada Brasil em contra-reforma: desestruturação do Estado e perda de direitos, de autoria de Elaine Rossetti Behring.
} 
período de validade do mesmo é que nas tabelas aparecerá 2017 como a última referência de ano, pois se trata do ano em que foi firmado o último acordo coletivo analisado neste estudo; mas, por ter validade também em vários meses de 2018, é que utilizamos essa referência temporal no corpo do texto.

Dito isso, ainda importa ressaltar que, entre os anos de 2009 e 2014, os acordos coletivos tinham vigência de dois anos, após, passaram a ser anuais.

Em caso de não cumprimento do acordo firmado, foi estabelecida uma multa de R\$ 100,00. Para o 'Acompanhamento do Acordo' foi estabelecido que seriam realizadas reuniões trimestrais durante o período (ano) de sua vigência, sendo que, na última dessas reuniões, seriam apresentadas as propostas a serem pactuadas no acordo seguinte, e as partes seriam avisadas e chamadas com 15 dias de antecedência, antes do término do acordo em vigência, para o fechamento do novo acordo e posterior assinatura deste. Não houve alteração dessas questões nos acordos coletivos ao longo dos anos analisados. Acerca do repasse aos sindicatos, que ocorre por meio de desconto na folha de pagamento dos trabalhadores sindicalizados no $5^{\circ}$ dia útil de cada mês, destaca-se que tal questão também não sofreu alteração entre as partes no período analisado.

Para uma melhor realização e compreensão da análise, os dados foram agrupados em quatro categorias de cláusulas que foram organizadas em tabelas, sendo: 1) Cláusulas trabalhistas (salariais); 2) Cláusulas sociais; 3) Acordos e Benefícios referentes à área da saúde (auxílios médicos e odontológicos) e 4) Acordos e Benefícios referentes à área da família (cônjuges e filhos).

É relevante destacar, acerca da organização dos trabalhadores e dos acordos coletivos, que tais pactuações, após firmadas, abrangem e contemplam todos os trabalhadores das minas da Vale S.A. nas quais o Metabase Inconfidentes possui base territorial de atuação, sejam estes trabalhadores sindicalizados ou não, e independentemente do tempo de contratação pela empresa; mas considerando, obviamente, a particularidade de cada profissão/categoria e a possibilidade de os trabalhadores serem representados por outros sindicatos de categoria, situação que é recorrente no trabalho na mineração.

Dito isso, ressalta-se que os benefícios garantidos nas cláusulas dos acordos abrangem de forma ampla o conjunto de trabalhadores, o que reconhecemos como uma grande conquista de classe. Em contraposição, consideramos como uma estratégia de fragmentação e apaziguamento das lutas o fato de que é possível que trabalhadores que atuam nas minas não sejam representados por esse sindicato, como é o caso dos trabalhadores terceirizados e 
dos que são representados pelos sindicatos de suas categorias profissionais e não pelo ramo de atuação.

Os dados a seguir estão organizados na tabela 1 e nos informam sobre as cláusulas trabalhistas. Acerca do reajuste do Salário Base, é perceptível que a categoria teve um reajuste mais significativo nos anos de 2011, com uma porcentagem de 8,6\%, e de 2016, com 8,5\%. Dentre os anos de menor valor reajustado, destacamos o ano de 2017 com uma porcentagem de apenas 2,5\%. Destaca-se que não houve aumento significativo na média salarial, que ficou estabelecida em $\mathrm{R} \$ 1.253,84$. Acerca disso é relevante explicitar que o piso salarial é considerado como base de cálculo para o pagamento do adicional de insalubridade, o que interfere diretamente na remuneração total recebida pelos trabalhadores.

O Abono Salarial, que é um benefício repassado para os trabalhadores através de um valor que é desvinculado do salário, nos anos de 2009 e 2010, foi de R \$600,00 e de 2011 a 2014, de R \$700,00. O aumento mais considerável deste benefício aconteceu no ano de 2015, cujo valor foi de $R \$ 4.660,00$. Essa grande diferença deve-se ao fato de que a mineradora Vale S.A. foi responsável por um significativo aumento da atividade de extração de minério de ferro na região e, com isso, teve, consequentemente, um aumento expressivo de seus lucros naquele período.

Destacamos que foi em 05 de novembro de 2015 que aconteceu o rompimento/crime da barragem de Fundão em Mariana - MG de propriedade da Samarco S.A., BHP Billiton e Vale S.A. Relacionamos tal acontecimento diretamente com o aumento da produção/extração de minério de ferro e com a superexploração da força de trabalho nessa atividade produtiva. (BERTOLLO, 2017). Enfatizamos que os trabalhadores vinculados à atividade da mineração nesse município são representados pelo Sindicato Metabase Mariana, sendo esse o motivo de não abordarmos mais diretamente o rompimento/crime no texto ora apresentado.

No entanto, mesmo que os dados dos acordos coletivos analisados não se refiram diretamente às pactuações entre a mineradora responsável pelo rompimento/crime (Samarco S.A.) e o sindicato que representa os trabalhadores a ela vinculados (Metabase Mariana), é imperioso destacar a relação direta entre o dado correspondente ao valor repassado via abono salarial no ano de 2015 e o rompimento/crime, pois explicita que todo o contexto produtivo nas diferentes empresas mineradoras e minas de suas propriedades foi levado ao extremo, ou seja, houve um aumento da extração e consequentemente dos lucros. Isso evidencia a 
posição conscientemente assumida pelas mineradoras de atenuar o contexto altamente degradante e destrutivo a que são submetidos os trabalhadores, ou seja, opta-se e pactua-se legalmente a distribuição de parte (irrisória) do montante financeiro adquirido pela empresa, porém se vai às últimas consequências no que se refere à produção desenfreada de minério de ferro na região. ${ }^{7}$

O valor do adicional noturno, que é direito dos trabalhadores no horário de $22 \mathrm{~h}$ até às $5 \mathrm{~h}$ do dia seguinte, é referido ao valor da hora calculada com base no Salário Base. Nos acordos coletivos, os valores são de $60 \%$, divididos em $20 \%$ e $40 \%$ conforme o horário trabalhado. Os valores do adicional noturno de $20 \%$ se mantiveram ao longo dos anos, já os valores de $40 \%$ passaram, a partir de 2013 , para $45 \%$ do valor da hora de trabalho de cada funcionário.

Quanto ao pagamento de horas extras, os trabalhadores não obtiveram maiores ganhos. Os valores se mantiveram os mesmos ao longo dos nove anos analisados, sendo que, nas duas primeiras horas extras de trabalho, o percentual a ser pago foi de 50\%; a partir da terceira hora, foi de $110 \%$; e, para as horas extras trabalhadas em dia de repouso semanal, feriado, fins de semana ou dia que não seja de expediente do trabalhador, ficou estabelecido em $120 \%$. Acerca da antecipação do $13^{\circ}$ Salário, foi estabelecido que o pagamento de $50 \%$ do salário ocorreria no mês de novembro de cada ano e os demais 50\% seriam pagos no mês de dezembro. Essa cláusula não é diferente das regras da CLT.

O Bônus Por Acordo de Dois Anos caracteriza-se como mesmo benefício do Abono Salarial. Nos anos de 2009 a 2014, os acordos coletivos tinham vigência de dois anos, dessa forma, o valor do abono a ser pago aos trabalhadores se referia ao período de vigência do acordo; no entanto, o pagamento era dividido em parcelas anuais. No ano de 2009 o valor do bônus foi de $\mathrm{R} \$ 1.200,00$, sendo pago $\mathrm{R} \$ 600,00$ no ano de 2009 e $\mathrm{R} \$ 600,00$ no ano de 2010. No ano de 2011, o valor acordado foi de $\mathrm{R} \$ 1.400,00$, sendo repassado aos trabalhadores R \$ 700,00 no ano de 2011 e a mesma quantia em 2012. O mesmo ocorreu até 2014, quando os acordos passaram a ser firmados anualmente e o bônus extinto.

\footnotetext{
${ }^{7}$ Para maior conhecimento sugerimos a leitura da tese de doutorado intitulada 'Mineração e superexploração da força de trabalho: análise a partir da realidade de Mariana - MG', apresentada e defendida no Programa de Pós-graduação em Serviço Social da Universidade Federal de Santa Catarina no ano de 2017 e de autoria de Kathiuça Bertollo, bem como, apontamos a relevância e a pertinência da realização de novos estudos sobre a temática.
} 
Tabela 1: Dados referentes às cláusulas trabalhistas nos acordos firmados entre o Sindicato Metabase Inconfidentes e Vale S.A. e com validade no período de 2009 a 2018

\begin{tabular}{|c|c|c|c|c|c|c|c|c|c|c|c|}
\hline \multirow{2}{*}{\multicolumn{2}{|c|}{ CLÁUSLAS TRABALHISTAS }} & \multicolumn{10}{|c|}{ ANOS } \\
\hline & & 2009 & 2010 & 2011 & 2012 & 2013 & 2014 & 2015 & 2016 & 2017 & MÉDIA \\
\hline & REAJUSTE SALÁRIO BASE & $7,0 \%$ & $7,0 \%$ & $8,6 \%$ & $8,0 \%$ & $6,0 \%$ & $5,4 \%$ & $0,0 \%$ & $8,5 \%$ & $2,5 \%$ & $5,9 \%$ \\
\hline & ABONO SALARIAL & $\mathrm{R} \$ 600,00$ & $\mathrm{R} \$ 600,00$ & $\mathrm{R} \$ 700,00$ & $\mathrm{R} \$ 700,00$ & $\mathrm{R} \$ 700,00$ & $\mathrm{R} \$ 700,00$ & $\mathrm{R} \$ 4.660,00$ & $\mathrm{R} \$ 0,00$ & $\mathrm{R} \$ 0,00$ & $\mathrm{R} \$ 962,22$ \\
\hline & PISO SALARIAL & $R \$ 930,00$ & $\mathrm{R} \$ 1.000,00$ & $\mathrm{R} \$ 1.000,00$ & $\mathrm{R} \$ 1.250,00$ & $\mathrm{R} \$ 1.325,00$ & $\mathrm{R} \$ 1.325,00$ & $\mathrm{R} \$ 1.396,55$ & $\mathrm{R} \$ 1.515,00$ & $\mathrm{R} \$ 1.542,99$ & $R \$ 1.253,84$ \\
\hline ADICIONAL & $\mathrm{L}$ até às 23:55h & $20 \%$ & $20 \%$ & $20 \%$ & $20 \%$ & $20 \%$ & $20 \%$ & $20 \%$ & $20 \%$ & $20 \%$ & $20,0 \%$ \\
\hline NOTURNO & de 23:55h às 5:00h & $40 \%$ & $40 \%$ & $40 \%$ & $40 \%$ & $45 \%$ & $45 \%$ & $45 \%$ & $45 \%$ & $45 \%$ & $42,8 \%$ \\
\hline \multirow{3}{*}{$\begin{array}{l}\text { HORAS } \\
\text { EXTRAS }\end{array}$} & Duas Primeiras horas & $50 \%$ & $50 \%$ & $50 \%$ & $50 \%$ & $50 \%$ & $50 \%$ & $50 \%$ & $50 \%$ & $50 \%$ & $50,0 \%$ \\
\hline & A partir da terceira hora & $110 \%$ & $110 \%$ & $110 \%$ & $110 \%$ & $110 \%$ & $110 \%$ & $110 \%$ & $110 \%$ & $110 \%$ & $110,0 \%$ \\
\hline & Feriados e fins de semana & $120 \%$ & $120 \%$ & $120 \%$ & $120 \%$ & $120 \%$ & $120 \%$ & $120 \%$ & $120 \%$ & $120 \%$ & $120,0 \%$ \\
\hline \multicolumn{2}{|r|}{ ANTECIPAÇÃO do 13 ㅇalário } & $50 \%$ & $50 \%$ & $50 \%$ & $50 \%$ & $50 \%$ & $50 \%$ & $50 \%$ & $50 \%$ & $50 \%$ & $50,0 \%$ \\
\hline \multicolumn{2}{|c|}{ BÔNUS por acordo de 2 anos } & $\mathrm{R} \$ 1.200,00$ & $\mathrm{R} \$ 1.200,00$ & $\mathrm{R} \$ 1.400,00$ & $\mathrm{R} \$ 1.400,00$ & $\mathrm{R} \$ 1.400,00$ & $\mathrm{R} \$ 1.400,00$ & $\mathrm{R} \$ 0,00$ & $\mathrm{R} \$ 0,00$ & $\mathrm{R} \$ 0,00$ & $\mathrm{R} \$ 888,89$ \\
\hline \multicolumn{2}{|c|}{ MULTA entre as partes por não cumprir o acordo } & $R \$ 100,00$ & $R \$ 100,00$ & $R \$ 100,00$ & $\mathrm{R} \$ 100,00$ & $R \$ 100,00$ & $\mathrm{R} \$ 100,00$ & $R \$ 100,00$ & $\mathrm{R} \$ 100,00$ & $R \$ 100,00$ & $R \$ 100,00$ \\
\hline
\end{tabular}

Fonte: Autoria própria.

Os dados a seguir estão organizados na Tabela 2 e nos informam sobre as cláusulas sociais. Acerca do Cartão Alimentação fornecido aos trabalhadores pela Vale S.A., é importante ressaltar que o trabalhador participa com $5 \%$ do custo total do benefício. No ano de 2009, o valor mensal que os trabalhadores receberam foi de R \$320,00. De 2011 a 2012, passa a ser de $\mathrm{R} \$ 500,00$. Em 2013 ocorre um aumento de $\mathrm{R} \$ 120,00$, permanecendo o valor desse auxílio em $\mathrm{R} \$ 620,00$ até o ano de 2016, quando é conquistado um novo aumento, porém de somente $\mathrm{R} \$ 80,00$. A situação piora no acordo referente aos anos de 2017 e 2018 , pois o aumento conquistado foi mais irrisório ainda, somente $\mathrm{R} \$ 17,00$. O que os acordos explicitam sobre esse direito é que ocorreu uma desvalorização expressiva no valor recebido, considerando que o preço dos alimentos aumentou ao longo dos anos, situação que é cotidianamente sentida pela classe trabalhadora brasileira $^{8}$. No período analisado, a média total recebida via cartão alimentação foi de $\mathrm{R} \$ 546,33$.

De acordo com o que consta nos itens 18 e 18.1 dos acordos coletivos e que dispõem sobre o Reembolso Educacional:

\footnotetext{
A empresa reembolsará os seus empregados com as despesas incorridas por esses cursos de ensino fundamental, ensino médio e ensino superior em curso de graduação (a partir da autorização de funcionamento pelo Ministério da Educação), nos termos da Instrução INS-0036. (ACORDOS COLETIVOS DE TRABALHO, 2009 - 2017)
}

Assim, nos anos de 2009 até 2018, o reembolso dos trabalhadores que cursaram o nível médio foi de $90 \%$; já para os trabalhadores que cursaram o ensino superior o reembolso foi

\footnotetext{
${ }^{8}$ Para maior conhecimento desta situação de aumento do preço dos produtos alimentícios, da inflação e do preço da cesta básica, sugerimos consulta às publicações do Instituto de Pesquisa Econômica Aplicada (Ipea).
} 
de $75 \%$ até o ano de 2011, quando este percentual passou a ser de $85 \%$. Ressalta-se que as porcentagens de reembolso são baseadas no salário-base de cada trabalhador.

No percurso de análise das cláusulas sociais ainda foi possível constatar que o benefício de Cartão Material Escolar/Uniforme, que era fornecido no ano de 2009 no valor de R \$ 24,00, deixou de ser fornecido aos trabalhadores nos anos seguintes. Também, o benefício Vale Cultura, incentivado pelo governo federal como uma forma de integrar os trabalhadores à cultura e ao lazer, foi ofertado aos trabalhadores apenas de 2013 a 2015.

Tabela 2: Dados referentes às cláusulas sociais presentes nos acordos firmados entre o Sindicato Metabase Inconfidentes e a Vale S.A. e com validade no período de 2009 a 2018

\begin{tabular}{|c|c|c|c|c|c|c|c|c|c|c|c|}
\hline \multicolumn{2}{|c|}{ CLÁUSULAS SOCIAIS } & 2009 & 2010 & 2011 & 2012 & $\begin{array}{l}\text { ANO } \\
2013\end{array}$ & 2014 & 2015 & 2016 & 2017 & MÉDIA \\
\hline \multicolumn{2}{|c|}{ CARTÃO ALIMENTAÇÃO } & $\mathrm{R} \$ 320,00$ & $\mathrm{R} \$ 320,00$ & $\mathrm{R} \$ 500,00$ & $\mathrm{R} \$ 500,00$ & R\$620,00 & $R \$ 620,00$ & $\mathrm{R} \$ 620,00$ & $\mathrm{R} \$ 700,00$ & $\mathrm{R} \$ 717,00$ & $\mathrm{R} \$ 546,33$ \\
\hline \multirow{2}{*}{ REEMBOLSO EDUCACIONAL. } & Ensino Médio & $90 \%$ & $90 \%$ & $90 \%$ & $90 \%$ & $90 \%$ & $90 \%$ & $90 \%$ & $90 \%$ & $90 \%$ & $90 \%$ \\
\hline & Ensino superior & $75 \%$ & $75 \%$ & $85 \%$ & $85 \%$ & $85 \%$ & $85 \%$ & $85 \%$ & $85 \%$ & $85 \%$ & $83 \%$ \\
\hline \multicolumn{2}{|c|}{ CARTÃO MATERIAL ESCOLAR/UNIFORME } & $\mathrm{R} \$ 24,00$ & $\mathrm{R} \$ 24,00$ & $\mathrm{R} \$ 24,00$ & $\mathrm{R} \$ 24,00$ & $\mathrm{R} \$ 0,00$ & $\mathrm{R} \$ 0,00$ & $\mathrm{R} \$ 0,00$ & $\mathrm{R} \$ 0,00$ & $\mathrm{R} \$ 0,00$ & $R \$ 10,67$ \\
\hline \multicolumn{2}{|c|}{ VALE CULTURA } & $\mathrm{R} \$ 0,00$ & $\mathrm{R} \$ 0,00$ & $\mathrm{R} \$ 0,00$ & $R \$ 0,00$ & $\mathrm{R} \$ 50,00$ & $R \$ 50,00$ & $\mathrm{R} \$ 50,00$ & $R \$ 0,00$ & $\mathrm{R} \$ 0,00$ & $\mathrm{R} \$ 16,67$ \\
\hline \multicolumn{2}{|c|}{ REPASSE AOS SINDICATOS } & \multicolumn{10}{|c|}{ Descontos no 5² dia útil do mês, na folha de pagamento dos associados (não houve alteração entre 2009 à 2017). } \\
\hline \multicolumn{2}{|c|}{ ACOMPANHAMENTO DO ACORDO } & & & & om 15 dias & de antecedê & ncialnãoho & urateras? & Inentre 30 & 9 à 2017). & \\
\hline
\end{tabular}

Fonte: Autoria própria.

Os dados a seguir estão organizados na Tabela 3 e nos informam sobre os Acordos e Benefícios referentes à área da saúde (auxílios médicos e odontológicos). Entre os anos de 2009 a 2017, as Despesas com Tratamento Psicológico e Psicoterápico tiveram um reembolso de $40 \%$ com cada tipo de tratamento. Esse valor se manteve ao longo dos anos e os limites do reembolso são de acordo com o limite máximo. Dos valores analisados, a média total final do limite semestral clínico foi de $\mathrm{R} \$ 1.279,98$ e a média final do limite do reembolso de $40 \%$ do tratamento em regime de internação foi de $\mathrm{R} \$ 2.559,88$ por beneficiário.

O benefício do reembolso das Despesas com Vacinas também manteve os mesmos requisitos anteriores, isto é, a Vale S.A. reembolsaria o valor de $40 \%$ das despesas com vacinas utilizadas para prevenção de doenças infectocontagiosas devidamente registradas pelo Ministério da Saúde. Dentre os valores analisados e demonstrados na Tabela 3, a média final do limite do valor do reembolso é de $40 \%$ do total de $\mathrm{R} \$ 234,16$ reais.

O Reembolso das Despesas Médicas de Grande Risco permaneceu com o percentual de participação da Vale S.A. em 70\%. O Reembolso das Despesas Médicas de Pequeno Risco foi de $65 \%$ nos anos de 2009 a 2015. A partir de 2015 e até 2018 esse valor foi reduzido para 55\%, ou seja, uma perda considerável para o trabalhador, de $10 \%$ desse benefício. As 
Despesas de grande Porte com Internação permaneceram com $99 \%$ de reembolso pela Vale S.A. ao longo dos anos 2009 até 2018. Em relação ao Atendimento Odontológico, a empresa participou com o reembolso de $65 \%$ do valor total do tratamento até o ano de 2015 e, deste ano em diante, o valor do reembolso foi reduzido para 55\%. Para a compra de medicamentos especiais, o valor do reembolso foi de $60 \%$, e esse valor permaneceu o mesmo até o ano de 2018. Nos acordos coletivos realizados nos últimos anos do período considerado, os trabalhadores perderam alguns benefícios do Plano Odontológico, tais como o direito à prótese dentária e a tratamentos odontológicos mais específicos. Dessa forma, pode-se afirmar que, em questões de benefícios de saúde em geral, os trabalhadores não perderam tanto como em relação à questão específica de tratamento odontológico.

Tabela 3: Dados referentes às cláusulas da saúde presentes nos acordos firmados entre o Sindicato Metabase Inconfidentes e Vale S.A. e com validade no período de 2009 a 2018

\begin{tabular}{|c|c|c|c|c|c|c|c|c|c|c|c|}
\hline \multirow{2}{*}{\multicolumn{2}{|c|}{ CLÁUSULAS DA SAÚdE }} & \multirow{3}{*}{$\frac{2009}{40 \%}$} & \multirow{3}{*}{$\frac{2010}{40 \%}$} & \multirow{3}{*}{$\frac{2011}{40 \%}$} & \multirow{3}{*}{$\frac{2012}{40 \%}$} & \multirow{3}{*}{$\begin{array}{l}\text { ANO } \\
2013 \\
40 \%\end{array}$} & \multirow{3}{*}{$\frac{2014}{40 \%}$} & \multirow{3}{*}{$\frac{2015}{40 \%}$} & \multirow{3}{*}{$\frac{2016}{40 \%}$} & \multirow{3}{*}{$\frac{2017}{40 \%}$} & \multirow{2}{*}{ Média } \\
\hline & & & & & & & & & & & \\
\hline \multirow{3}{*}{$\begin{array}{l}\text { DESPESAS COM } \\
\text { TRATAMENTO } \\
\text { PSICOLÓGICO } \\
\text { PSICOTERAPTICO }\end{array}$} & Repasse & & & & & & & & & & $40 \%$ \\
\hline & $\begin{array}{l}\text { Limite semestral } \\
\text { (clinico) }\end{array}$ & $\mathrm{R} \$ 1.007,51$ & $\mathrm{R} \$ 1.007,51$ & $\mathrm{R} \$ 1.158,88$ & $\mathrm{R} \$ 1.158,88$ & $\mathrm{R} \$ 1.340,47$ & $\mathrm{R} \$ 1.340,47$ & $\mathrm{R} \$ 1.412,64$ & $\mathrm{R} \$ 1.532,71$ & $\mathrm{R} \$ 1.560,76$ & $\mathrm{R} \$ 1.279,98$ \\
\hline & $\begin{array}{l}\text { Limite semestral } \\
\text { (internação) }\end{array}$ & $R \$ 2.015,02$ & $\mathrm{R} \$ 2.015,02$ & $\mathrm{R} \$ 2.317,77$ & $\mathrm{R} \$ 2.317,77$ & $\mathrm{R} \$ 2.680,54$ & $\mathrm{R} \$ 2.680,54$ & $\mathrm{R} \$ 2.825,29$ & $\mathrm{R} \$ 3.065,44$ & $\mathrm{R} \$ 3.121,54$ & $\mathrm{R} \$ 2.559,88$ \\
\hline \multirow[b]{2}{*}{$\begin{array}{l}\text { DESPESAS COM } \\
\text { VACINAS }\end{array}$} & Repasse & $40 \%$ & $40 \%$ & $40 \%$ & $40 \%$ & $40 \%$ & $40 \%$ & $40 \%$ & $40 \%$ & $40 \%$ & $40 \%$ \\
\hline & $\begin{array}{l}\text { Limite por } \\
\text { vacina }\end{array}$ & $\mathrm{R} \$ 184,32$ & $\mathrm{R} \$ 184,32$ & $\mathrm{R} \$ 212,01$ & $\mathrm{R} \$ 212,01$ & $R \$ 245,20$ & $\mathrm{R} \$ 245,20$ & $\mathrm{R} \$ 258,44$ & $R \$ 280,41$ & $\mathrm{R} \$ 285,54$ & 234,16 \\
\hline \multirow{2}{*}{$\begin{array}{l}\text { REEMBOLSO DE } \\
\text { DESPESAS MÉDICAS }\end{array}$} & Grande Risco & $70 \%$ & $70 \%$ & $70 \%$ & $70 \%$ & $70 \%$ & $70 \%$ & $70 \%$ & $70 \%$ & $70 \%$ & $70 \%$ \\
\hline & Pequeno Risco & $65 \%$ & $65 \%$ & $65 \%$ & $65 \%$ & $65 \%$ & $65 \%$ & $55 \%$ & $55 \%$ & $55 \%$ & $62 \%$ \\
\hline \multicolumn{2}{|c|}{$\begin{array}{l}\text { REEBOLSO DEDESPESAS } \\
\text { ODONTOLÓGICAS }\end{array}$} & $50 \%$ & $50 \%$ & $50 \%$ & $50 \%$ & $50 \%$ & $50 \%$ & $50 \%$ & $50 \%$ & $50 \%$ & $50 \%$ \\
\hline \multicolumn{2}{|c|}{$\begin{array}{l}\text { DESPESAS DE GRANDE RISCO } \\
\text { (INTERNAÇÃO) }\end{array}$} & $99 \%$ & $99 \%$ & $99 \%$ & $99 \%$ & $99 \%$ & $99 \%$ & $99 \%$ & $99 \%$ & $99 \%$ & $99 \%$ \\
\hline \multicolumn{2}{|c|}{ ATENDIMENTO ODONTOLÓGICO } & $65 \%$ & $65 \%$ & $65 \%$ & $65 \%$ & $65 \%$ & $65 \%$ & $55 \%$ & $55 \%$ & $55 \%$ & $62 \%$ \\
\hline \multicolumn{2}{|c|}{ MEDICAMENTOS ESPECIAIS } & $60 \%$ & $60 \%$ & $60 \%$ & $60 \%$ & $60 \%$ & $60 \%$ & $60 \%$ & $60 \%$ & $60 \%$ & $60 \%$ \\
\hline
\end{tabular}

Fonte: Autoria própria.

Os dados a seguir estão organizados na Tabela 4 e nos informam sobre os acordos e benefícios referentes à área da família (cônjuges e filhos). Pode-se destacar, em relação ao Auxílio Creche/Maternal, que é concedido $100 \%$ de reembolso no caso de atendimento a filho até o $36^{\circ}$ mês de vida; e $60 \%$ de reembolso no caso de atendimento a filho do $37^{\circ}$ ao $72^{\circ}$ mês de vida. O valor máximo de limite de reembolso desse benefício aumentou entre 2009 e 2014, passando de $\mathrm{R} \$ 245,48$ para $\mathrm{R}$ \$ 327,22; no entanto, não foi possível localizar informações sobre esse benefício nos acordos firmados nos anos seguintes. Percebe-se que esse benefício fomenta muito fortemente a rede privada de educação no município de Mariana - MG e região. Fomento este que se dá em detrimento do ensino público, mas que, por deixar de constar nos acordos, significa, contraditoriamente, uma perda relevante para 
os trabalhadores e para seus filhos, que não necessariamente conseguirão uma vaga na rede pública de atendimento.

Para a Trabalhadora Gestante Mãe a empresa garantirá o emprego ou o salário de 120 dias após licença maternidade. No item 28 dos acordos coletivos é garantida a transferência Provisória da Gestante:

com base no artigo 392, § $4^{\circ}$ da CLT, à empregada gestante é assegurado o direito de transferência provisória do setor ou função, quando as condições de saúde exigir, desde que haja prévia comprovação desta necessidade através de laudo médico emitido ou aprovado pelo médico do trabalho da empresa. (ACORDOS COLETIVOS DE TRABALHO, 2009 - 2017)

Já para o Trabalhador Empregado Pai, a empresa garantirá o emprego ou o salário por 60 dias após o nascimento do filho.

O Benefício de Saúde do Cônjuge (tratamento de saúde) é oferecido a todos, com os mesmos direitos, considerando companheiro também pessoas do mesmo sexo. Esse benefício consta no item 10.3 do acordo:

A empresa considerará o cônjuge e, nos termos de seu regulamento, o (a) companheiro (a), inclusive do mesmo sexo, como dependente do empregado para efeitos de assistência médica supletiva, independente da data de admissão do mesmo na empresa e da renda percebida. (ACORDOS COLETIVOS DE TRABALHO, 2009 - 2017).

Percebe-se que há certo avanço no que se refere ao reconhecimento e ao tratamento ético e digno das relações familiares dos trabalhadores, sejam elas hétero ou homoafetivas.

No tocante ao benefício "da mãe de filho adotivo" a empresa agirá nos termos da Lei 10.421, de 15 de abril de 2002, ou seja, a empresa concederá licença maternidade à trabalhadora que adotar ou obtiver guarda judicial para fins de adoção de criança até 8 anos. O período dos benefícios, conforme a referida lei, é configurado da seguinte forma: para crianças de até 1 ano de idade a licença para a mãe trabalhadora será de 120 dias; para crianças de 1 ano até 4 anos, será de 60 dias; e para crianças de 4 a 8 anos, será de 30 dias. 
Tabela 4: Dados referentes às cláusulas da área familiar presentes nos acordos firmados entre o Sindicato Metabase Inconfidentes e Vale S.A. e com validade no período de 2009 a 2018

\begin{tabular}{|c|c|c|c|c|c|c|c|c|}
\hline \multirow{2}{*}{\multicolumn{2}{|c|}{ CLÁUSULAS DA ÁREA FAMILIAR }} & \multicolumn{7}{|c|}{ ANO } \\
\hline & & 2009 & 2010 & 2011 & 2012 & 2013 & 2014 & $2015 \quad 2016 \quad 2017$ \\
\hline \multirow{3}{*}{$\begin{array}{l}\text { AUXÍLIO CRECHE/ } \\
\text { MATERNAL }\end{array}$} & Reembolso (até 36 meses) & $100 \%$ & $100 \%$ & $100 \%$ & $100 \%$ & $100 \%$ & $100 \%$ & \multirow{3}{*}{$\begin{array}{c}\text { Valores não } \\
\text { encontrados entre } \\
2015 \text { e } 2017 .\end{array}$} \\
\hline & Reembolso (de 37 a 72 meses) & $60 \%$ & $60 \%$ & $60 \%$ & $60 \%$ & $60 \%$ & $60 \%$ & \\
\hline & Limite máximo & $\mathrm{R} \$ 245,48$ & $R \$ 245,48$ & $\mathrm{R} \$ 285,83$ & $\mathrm{R} \$ 285,83$ & $\mathrm{R} \$ 327,22$ & $\mathrm{R} \$ 327,22$ & \\
\hline \multicolumn{2}{|c|}{ EMPREGADA GESTANTE MÃE } & \multicolumn{7}{|c|}{ A EMPRESA GARANTIRÁ O EMPRREGO OU SALÁRIO 120 DIAS, APÓS LICENÇA MATERNIDADE. } \\
\hline \multicolumn{2}{|c|}{ EMPREGADO PAI } & \multicolumn{7}{|c|}{ GARANTIA DO EMPREGO OU SALÁRIO POR 60 DIAS, APÓS NASCIMENTO DO FILHO. } \\
\hline \multicolumn{2}{|c|}{ SAÚDE DO CONJUGE (TRATAMENTO DE SAÚDE) } & \multicolumn{7}{|c|}{ MESMOS DIREITOS, CONSIDERA-SE COMPANHEIRO INCLUINDO PARCEIRO DO MESMO SEXO. } \\
\hline \multirow{3}{*}{$\begin{array}{l}\text { LICENÇA À MÃE DO FILHO } \\
\text { ADOTIVO (LEI:10.421 DE } \\
\text { ABRIL DE 2012) }\end{array}$} & Crianças até 1 ano & \multicolumn{7}{|c|}{120 dias } \\
\hline & Crianças de 1 a 4 anos & \multicolumn{7}{|c|}{60 dias } \\
\hline & Crianças de 4 a 8 anos & \multicolumn{7}{|c|}{30 dias } \\
\hline
\end{tabular}

Fonte: Autoria própria.

Após apresentarmos os principais elementos presentes nos acordos coletivos estudados, consideramos que a luta de classes no âmbito das relações trabalhistas entre o Sindicato Metabase Inconfidentes e a Vale S.A. é real e se põe, se explicita e se reafirma em cada pactuação realizada. Situação essa que pode ser relacionada com a questão da privatização da mineradora, com as modificações e os impactos desse acontecimento no que se refere aos direitos e condições de trabalho quando a Vale ainda era uma empresa estatal e após a sua privatização.

Importa ressaltar que, pela metodologia assumida neste estudo ora apresentado, não conseguiremos abordar de modo mais incisivo essa questão tão polêmica e questionável da privatização da Companhia Vale do Rio Doce e de como o processo aconteceu. O que faremos é destacar alguns elementos presentes nas relações entre o Sindicato Metabase Inconfidentes e a mineradora antes e depois da privatização, pois compreendemos que esses subsidiam e potencializam o entendimento do contexto em que as pactuações anteriormente demonstradas ocorreram. Assim, destacamos a partir de CARRANO (2017 apud BERTOLLO, 2017, p. 132) que

a Vale do Rio Doce (hoje apenas Vale) foi vendida por R\$ 3,3 bilhões, quando somente as suas reservas minerais eram calculadas em mais de $\mathrm{R} \$ 100$ bilhões à época. [...] A empresa foi criada em 1942 com recursos do Tesouro Nacional. Durante 55 anos, foi uma empresa mista e o seu controle acionário pertencia ao governo. Depois do leilão de privatização da companhia, com militância ativa de José Serra, ministro do planejamento à época, a Vale passou a ser comandada pelo banco Bradesco, integrante do consórcio Valepar, detentor de 32 por cento das ações, enquanto os investidores estrangeiros passaram a somar $26,7 \%$ das ações totais da empresa. 
Essa informação explicita uma posição de classe assumida pelo Estado brasileiro, ou seja, entreguista dos bens e patrimônios públicos ao capital internacional, posição esta que reafirma as teses de Marini (2005) acerca do caráter dependente e subordinado do capitalismo no continente latino-americano e do papel desempenhado pelo Estado neste contexto. Essa opção política e financeira de condução do Estado-nação é alinhada e incorporada às premissas neoliberais que, especialmente a partir da segunda metade do século XX e nesta primeira década do século XXI, apenas reafirmam, perpetuam e agravam a condição de dependência do país em relação aos países de capitalismo central, ou seja, aos países que detém um maior poderio econômico e político decorrente do lugar que ocupam na divisão internacional do trabalho, e que, por consequência, ditam as regras a serem seguidas pelos países de capitalismo dependente ${ }^{9}$. Ou seja, o processo de privatização da Companhia Vale do Rio Doce se deu em contexto de capitalismo dependente e subordinado; o que no tempo presente assume conformação cada vez mais agravada, incidindo de forma destrutiva sobre a força de trabalho, no caso em tela, sobre os trabalhadores da mineração extrativista na Região Inconfidentes de Minas Gerais.

O embate entre as partes, isto é, os elementos e contornos da luta de classes presentes no processo produtivo e nas relações de trabalho na mineração e que tem incidência na pactuação dos acordos coletivos firmados entre o Sindicato Metabase Inconfidentes e a Vale, antes e após a privatização da mineradora, assume as seguintes conformações:

\begin{abstract}
Se no período estatal, a produtividade era incentivada pelo apelo ao sentimento cívico de gerar divisas ao país, hoje ela tem várias outras formas de ser requerida: recompensa econômica coletiva, grupal ou individualizada (através da participação nos resultados e/ou nos lucros); metas estabelecidas e controladas dia a dia, e, não menos importante, a ameaça velada de um mercado de trabalho excessivamente inflacionado, frente a uma demanda da empresa cada vez mais reduzida. Hoje, as admissões são parcimoniosas e não acontecem na proporção necessária nos momentos de crescimento da demanda, e para cobrir necessidades eventuais a empresa usa o mecanismo das terceirizações. CARVALHO (2013, p. 93)
\end{abstract}

Esse contexto de acirramento das disputas, que, em última instância, significa a busca e a efetivação de maior exploração dos trabalhadores e de maior lucratividade da mineradora, é mais bem compreendido quando se explicitam as mudanças ocorridas na forma e nos meios de negociações, tais quais:

\footnotetext{
${ }^{9}$ Podemos referenciar as recomendações advindas do Consenso de Washington como exemplo desse "ditar as regras". Também, as inúmeras recomendações advindas do Banco Mundial e do Fundo Monetário Internacional, agências multilaterais que explicitam os interesses dos países de capitalismo central, do imperialismo sobre as nações e povos do globo como um todo, a fim de garantir e perpetuar os seus interesses e manutenção da condição de países e economias dominantes no capitalismo.
} 
De acordo com o Metabase/Inconfidentes, no período totalmente estatal, existiu uma coordenação nacional, na qual participavam, com funcionamento regular e profissional, mesmo com diferenças entre as várias tendências existentes na época, mas com muito mais maturidade política para entender essa necessidade. As demissões eram esporádicas, falava-se na época que se empregar na Vale era quase a mesma coisa que entrar no serviço público para o trabalhador comum. [...] As negociações coletivas aconteciam anualmente e os resultados eram os esperados. As reivindicações mais negociadas, em seu período totalmente estatal, foram a carteira de benefícios e direitos aprimorados durante o tempo, principalmente no que tange a assistência médica, salários e outros. Os benefícios sociais eram os investimentos nas cidades onde a CVRD tinha suas operações, como hospitais, moradia para os trabalhadores, clubes e outros. Eles não têm notícia de nenhum ano sem negociação. Ajuizaram apenas um dissídio coletivo na época de estatal (mas não especificaram a demanda). (CARVALHO, 2013, p. 102)

Após a privatização, o cenário se agrava, conforme pode ser observado na longa, mas importante citação do estudo da mesma autora:

(...) a relação do Metabase/Inconfidentes com a empresa privatizada não é positiva. De acordo com os dirigentes, após a privatização, a Vale deixou de repassar a mensalidade dos sócios do sindicato e não sentou com o sindicato para negociação de acordo coletivo, sendo que essa atitude demorou quase dois anos para ser resolvida. Afirmaram que as demissões promovidas pela empresa depois da privatização foram totalmente injustas, visando somente o lucro e o aumento de produtividade, geradas também pelo assédio de todos os tipos por causa do excesso de autoridade dos cargos de chefia. Ocorreram demissões em massa após a privatização, e a mais significativa foi a de 2008, na administração ex-presidente da empresa Roger Agnelli. Frente a isso, o sindicato participou de uma luta nacional, encabeçada por eles e pelo Metabase Itabira, com denúncias ao Ministério Público, atos com os movimentos sociais em várias cidades do estado de Minas Gerais, como em janeiro de 2009 em Itabira com 15 mil pessoas nas ruas e o de Mariana que reuniu 12 mil pessoas, denúncias na imprensa nacional e internacional, informes ao movimento sindical e social do mundo inteiro, denúncias na OIT e várias outras iniciativas. As negociações coletivas junto à empresa após a privatização são anuais. Ocorreram dois acordos com zero por cento de reajuste e uma pressão forte nas áreas com demissões. As reivindicações mais negociadas e os direitos conquistados foram: avanços mínimos na assistência médica supletiva, cartão alimentação, ganhos maiores nos salários variáveis e queda no custo fixo. Afirmam que a empresa continua fazendo "cortes secos" nos direitos após a privatização ou comprar benefícios via negociação. (CARVALHO, 2013, p. $107-108)$

Estas informações explicitadas por Carvalho (2013) somadas às que apresentamos acerca da análise dos acordos coletivos firmados entre o Sindicato Metabase Inconfidentes e a Vale S.A., com validade no período de 2009 a 2018, ou seja, passadas décadas da privatização da empresa pública, retratam o acirramento vivenciado no 'mundo do trabalho' e nas atividades laborais sob o domínio e a hegemonia do capital, mais especificamente do capital internacional; bem como, o fato de que esse contexto é e deve ser permeado pela luta organizada da classe trabalhadora no sentido de fazer enfrentamento às ofensivas e aos ataques vivenciados cotidianamente. 
Tal cenário é condição de sua própria existência enquanto relação de compra e venda da força de trabalho e de propriedade privada dos meios de produção, ou seja, da sociabilidade burguesa e das relações de trabalho conformadas no e pelo capitalismo enquanto modo de produção. Resgatando o clássico texto de Marx e Engels publicado originalmente em 1848, temos a seguinte afirmação sobre a sociabilidade que naquele momento se conformava e que ainda hoje se põe como determinante de nossas vidas e relações, dentre estas, as laborais: "A moderna sociedade burguesa, que surgiu do declínio da sociedade feudal, não aboliu as contradições de classe. Ela apenas colocou novas classes, novas condições de opressão e novas formas de luta no lugar das antigas." (MARX; ENGELS, 2008, p. 08).

\section{CONSIDERAÇÕES FINAIS}

Assumimos o entendimento de que o contexto da mineração extrativista na Região Inconfidentes de Minas Gerais, mais precisamente nos municípios de abrangência do Sindicato Metabase Inconfidentes, é fundamentado pela lógica da dependência, da superexploração da força de trabalho e da destruição ambiental. (BERTOLLO, 2017). Ressaltamos que este artigo, que possui um recorte de análise sobre as relações de trabalho, mais especificamente os acordos coletivos firmados entre o Sindicato Metabase Inconfidentes e a Vale S.A., não esgota e nem se aprofunda exaustivamente em tais questões, mas as identifica e as relaciona com a temática proposta.

Sendo a atividade minerária uma atividade extremamente danosa e penosa aos trabalhadores, à natureza e à vida social de seu entorno, há a necessidade de organização coletiva para tensionar, fazer frente e impor limites e negativas à premissa da exploração incontrolável almejada e imposta pelas empresas.

Nesse sentido ganha relevância a atuação sindical, enquanto um instrumento coletivo de apresentação de pautas, demandas e requisição de direitos trabalhistas. A partir do estudo realizado, podemos observar que este é um contexto de perdas e ganhos para os trabalhadores. Perdas que são expressão da ofensiva do capital, ou seja, das mineradoras sobre os trabalhadores, no sentido de lucrar cada vez mais a partir da negação de condições mínimas e adequadas de trabalho. Já os ganhos e a manutenção de direitos são devidos ao caráter combativo do sindicato Metabase Inconfidentes, de seus dirigentes e de sua base 
organizada, condição historicamente assumida pela entidade, conforme pudemos observar quando foi explicitada a relação com a mineradora antes e após sua privatização.

\begin{abstract}
As empresas tremem quando o Sindicato chega na mesa de negociação com um número alto de sindicalizados na base. Quando é assim, a empresa sabe que os trabalhadores estão unidos e que o Sindicato é forte! Quando o número de sindicalizados é alto, a empresa sempre pensa duas, três vezes antes de tentar passar o trabalhador para trás, já que ela sabe que se o trabalhador se revoltar, não tem produção. (ILAESE, 2019)
\end{abstract}

Ressaltamos que o contexto político, econômico e social do país - cujas marcas históricas vão da escravidão aos atuais ataques e ofensivas sobre os direitos sociais, trabalhistas e previdenciários a partir de modificações nas legislações via as chamadas 'reformas', que na verdade nada mais são do que 'contrarreformas' - bem como os rompimentos das barragens/crimes em Mariana - MG e Brumadinho - MG e a possibilidade iminente de novos rompimentos, tal como pode ocorrer em Ouro Preto - MG (G1 MINAS, 2020), apontam para a importância e necessidade de a classe trabalhadora se organizar.

Ressaltamos que há diferentes formas e meios pelos quais essa organização pode ocorrer, dentre os quais destacamos três sujeitos coletivos: o partido político, os movimentos sociais e os sindicatos. Ressaltamos que as posturas combativas do partido político são fundamentais no enfrentamento ao poderio político das mineradoras nos municípios, estados, bem como no país. Os governantes possuem um papel a ser desempenhado e para o qual foram eleitos e são os representantes da população. Nessa perspectiva, e buscando ir além da institucionalidade governamental burguesa, o partido também possui o estratégico papel de organização da classe no sentido de construir e buscar a transformação societária superando as violências da exploração capitalista.

Em relação aos movimentos sociais, especialmente aos que atuam diretamente na questão da mineração, dentre os quais destacamos o Movimento pela Soberania Popular na Mineração (MAM) e o Movimento dos Atingidos por Barragens (MAB), apontamos a pertinência de suas atuações no sentido de organizar as comunidades e as populações atingidas pela mineração e suas consequências danosas. Essa organização é cada dia mais necessária, considerando que o contexto de ofensiva das mineradoras se agrava, se amplia e se aprofunda.

Acerca da organização sindical, a análise das relações de trabalho e das disputas acerca das cláusulas dos acordos coletivos explicitam a relevância dessa organização coletiva dos trabalhadores, por se tratar do sujeito coletivo que os organiza e os representa 
no âmbito direto das negociações com o empregador. A partir dessa organização em sindicatos é fundamental que estes assumam uma postura combativa, que não assumam e sucumbam a posturas 'pelegas' e de alinhamento e submissão aos interesses das empresas em detrimento dos interesses dos trabalhadores. Especificamente no âmbito das relações de trabalho na mineração extrativista, é fundamental que seja rechaçado qualquer alinhamento com as mineradoras, expoentes do capital que nestas terras somente deixam um rastro de destruição, exploração e morte.

Por fim, recomendamos a pertinência de novos estudos sobre esta temática a fim de potencializar a produção de conhecimento e a disputa ideológica a partir do campo crítico na ciência, bem como para potencializar as lutas vivenciadas cotidianamente pelos trabalhadores e suas organizações a partir de sujeitos coletivos, especialmente via sindicatos.

\section{REFERÊNCIAS}

ACORDOS COLETIVOS DE TRABALHO. VALE S.A. e Sindicato dos Trabalhadores na Indústria de Extração de Ferro e Metais Básicos de Congonhas, Belo Vale e Ouro Preto. 2009 a 2017.

BERTOLLO, Kathiuça. Mineração e superexploração da força de trabalho: análise a partir da realidade de Mariana - MG. Tese (doutorado). Universidade Federal de Santa Catarina, Centro Sócio-Econômico, Programa de Pós-graduação em Serviço Social, Florianópolis, 2017.

CAHIS CONTRA CORRENTE. Centro Acadêmico de História da Universidade Federal de Ouro Preto. Nota do Sindicato Metabase Inconfidentes e da CSP Conlutas sobre o grave acidente na barragem da Samarco Mineração. 5 nov. 2015. Disponível em: https://cahiscontracorrente.wordpress.com/2015/11/06/nota-do-sindicato-metabaseinconfidentes-e-da-csp-conlutas-sobre-o-grave-acidente-na-barragem-da-samarcomineracao/. Acesso em: 01 jul 2017.

CARVALHO, Laura Nazaré de. Análise da ação dos sindicatos dos trabalhadores da mineradora Vale S.A. na região sudeste brasileira. Textos \& Debates, Boa Vista, n.23, p. 91-114, jan./jun. 2013. Disponível em: https://revista.ufrr.br/textosedebates/article/view/1623. Acesso em: 20 jul 2018.

ILAESE. Instituto Latino Americano de Estudos Socioeconômicos. Campanha Salarial dos Trabalhadores da Vale 2015, 2016, 2017, 2018. Disponível em: http://www.ilaese.org.br. Acesso em: 23 jul 2019.

ILAESE. Instituto Latino Americano de Estudos Socioeconômicos. Trabalho \& exploração: O mapa da exploração dos trabalhadores no Brasil. Ano 01, Vol. 01, 2017. 
ILAESE. Instituto Latino Americano de Estudos Socioeconômicos; SINDICATO METABASE INCONFIDENTES. As verdades que a Vale e os governos não mostram: Campanha salarial dos trabalhadores da Vale 2017-2018. 2017.

G1 Minas. Barragem da Vale em Ouro Preto entra no nível 2 de emergência. Disponível em: https://g1.globo.com/mg/minas-gerais/noticia/2020/04/01/barragem-da-vale-em-ouropreto-entra-no-nivel-2-de-

emergencia.ghtml?fbclid=IwAR2iX27z1NTGC_Nx0cwbfzc652IGu6kwxzzdtI18PRd5GkZ nPcO1DfAvVNs. Acesso em: 04 abr 2020.

LAMPIÃO. A mineração vale? In: Jornal-laboratório do Curso de Jornalismo da Universidade Federal de Ouro Preto. 34a ed. Ano 9. Julho de 2019.

MARINI, Ruy Mauro. Dialética da Dependência. In: Ruy Mauro Marini: vida e obra. TRANSPADINI, Roberta; STEDILE, João Pedro (orgs). 1 ed. São Paulo: Expressão Popular, 2005. p. 137 a 180.

MARX, Karl. O Capital: crítica da economia política. São Paulo: Boitempo, 2013. (Livro $1)$.

MARX, Karl; ENGELS, Friedrich. Manifesto do Partido Comunista. $1^{\text {a }}$ ed. São Paulo: Expressão Popular, 2008.

MATTOS, Marcelo Badaró. Trabalhadores e sindicatos no Brasil. 1 ed. São Paulo: Expressão Popular, 2009.

MILANEZ, Bruno et.al. A Estratégia Corporativa da Vale S.A.: um modelo analítico para Redes Globais Extrativas. Versos, Textos para Discussão PoEMAS, 2(2), p. 1-43. 2018.

OSÓRIO, Jaime. Padrão de reprodução do capital: uma proposta teórica. In: Padrão de reprodução do capital: contribuições da teoria marxista da dependência. FERREIRA, Carla; OSÓRIO, Jaime; LUCE, Mathias (orgs). São Paulo: Boitempo. 2012.

SINDICATO METABASE INCONFIDENTES. Disponível em: https://www.facebook.com/pg/metabaseinconfidentes/about/?ref=page_internal. Acesso em: 23 jul 2019.

WANDERLEY, Luiz Jardim. Do Boom ao Pós- Boom das commodities: o comportamento do setor mineral no Brasil. Versos: Textos para Discussão PoEMAS, v. 1, n. 1, p.1-7, ago. 2017. Disponível em: https://www.researchgate.net/publication/318213362_Do_Boom_ao_PosBoom_das_commodities_o_comportamento_do_setor_mineral_no_Brasil. Acesso em: 25 set 2017. 